\title{
TOLERÂNCIA À TOXICIDADE DE ALUMÍNIO DE LINHAGENS E HÍBRIDOS DE MILHO EM SOLUÇÃO NUTRITIVA ${ }^{(1)}$
}

\author{
MARIA ELISA AYRES GUIDETTI ZAGATTO PATERNIANI ${ }^{(2)}$; \\ PEDRO ROBERTO FURLANI ${ }^{(3)}$
}

\begin{abstract}
RESUMO
Avaliaram-se dez linhagens de milho do programa de melhoramento do Instituto Agronômico (IAC), em cruzamentos dialélicos e os 45 híbridos resultantes quanto à tolerância à toxicidade de alumínio em laboratório. Estimou-se a tolerância pelo comprimento líquido da radícula (CLR) de plântulas em solução nutritiva contendo 4,5 mg.L. $\mathrm{L}^{-1}$ de alumínio, em ensaio sob delineamento experimental de blocos casualizados com quatro repetições, utilizando-se como padrōes linhagens sensível e tolerante de IAC Taiúba. Apresentam-se, ainda, resultados da produtividade desses cruzamentos em ensaios de campo. Identificaramse linhagens que constituem fontes de tolerância (L 06 e L 09) e híbridos tolerantes à toxicidade de alumínio com elevada produtividade em solos corrigidos. $\mathrm{Na}$ análise dialélica, o desdobramento dos efeitos de tratamentos, em capacidade geral (CGC) e específica (CEC) de combinação, indicou a predominância de efeitos aditivos na manifestação da tolerância ao alumínio tóxico. Obtiveram-se elevados valores de heterose, indicando a existência de interações não alélicas na manifestação do CLR. O híbrido HS 10X11 (denominado IAC 21) aliou alta produtividade e tolerância ao alumínio, apresentando a maior estimativa da CEC para CLR.
\end{abstract}

Palavras-chave: Zea mays, genótipos, tolerância a Al, dialélico, capacidade de combinação.

\section{ABSTRACT \\ ALUMINUM TOXICITY TOLERANCE OF MAIZE INBRED LINES AND HYBRIDS EVALUATED IN NUTRIENT SOLUTION}

Ten inbred lines and the resulting forty-five hybrids from the maize IAC breeding program were evaluated for $\mathrm{Al}$ tolerance by the nutrient solution technique. Net radicle lengths (CLR) of plants grown with 4.5 $\mathrm{mg} . \mathrm{L}^{-1}$ were used to estimate $\mathrm{Al}$ tolerance. The experimental design was randomized complete block with four replications, and it was used two divergent inbred lines IAC Taiuba as control for Al tolerance and sensitivity, respectively. In addition to these data, it is shown also the grain yield of the same materials from field plots. It was identified two inbred lines (L 06 and L 09) as Al tolerance sources and hybrids potentially adapted to acid soil conditions (tolerant to $\mathrm{Al}$ toxicity). From the diallel analysis, the treatment effects were separated into general (CGC) and specific (CEC) combining ability and indicated the predominance of additive effects on the $\mathrm{Al}$ tolerance manifestation. High values of hybrid vigor were obtained, indicating the existence of interactions non-allelic in the manifestation of CLR. The hybrid HS 10X11 (named IAC 21) showed higher productivity and $\mathrm{Al}$ tolerance, and also a higher CEC estimate for CLR.

Key words: Zea mays, genotypes, Al tolerance, diallel, combining ability .

\section{INTRODUÇÃO}

A obtenção de cultivares tolerantes à toxicidade de alumínio vem despertando o interesse de muitas áreas da pesquisa agrícola, particularmente quando se pretende explorar eficientemente solos com acidez subsuperficial e elevado nível de alumínio, de difícil correção com manejo químico (Magnavaca e Bahia-Filho, 1995; Granados et al., 1993; Lopes et al., 1987; SaWAZAKI e Furlani, 1987; PANDEY et al., 1994).
Níveis elevados de alumínio impedem o crescimento radicular das plantas e, aliados a períodos de deficiência hídrica (veranicos), reduzem drasticamente a produtividade do milho, inviabilizando, às vezes, seu cultivo em área de solos ácidos.

A identificação de material genético tolerante pode oferecer importantes subsídios aos programas de melhoramento genético e à recomendação de cultivares visando ao melhor aproveitamento de solos ácidos

( $\left.{ }^{1}\right)$ Trabalho apresentado no I Congresso Brasileiro de Melhoramento de Plantas, em Goiânia (GO), em 2001. Parte de projeto com apoio financeiro da FAPESP. Recebido para publicação em 4 de julho de 2001 e aceito em 21 de fevereiro de 2002.

$\left({ }^{2}\right)$ Centro de Análise e Pesquisa Tecnológica do Agronegócio de Grãos e Fibras, Instituto Agronômico (IAC), Caixa Postal 28, 13001-970 Campinas (SP). E-mail: elisa@cec.iac.br

$\left({ }^{3}\right)$ Centro de Pesquisa e Desenvolvimento de Solos e Recursos Ambientais, IAC. E-mail: pfurlani@barao.iac.br 
(Furlani et al., 1986; Lima et al., 1995; Granados et al., 1993). Em milho, a maioria das variedades comerciais é suscetível ao alumínio tóxico, sendo a utilização de genótipos tolerantes uma alternativa adequada para elevar a eficiência da cultura em regiōes com limitação por acidez.

Um dos melhores índices para avaliar a tolerância ao $\mathrm{Al}$ em milho tem sido definido pelo crescimento da raiz seminal de plântulas desenvolvidas em solução nutritiva. O teste de solução nutritiva é conveniente, pois permite maior controle experimental e apresenta as seguintes vantagens: rapidez, menor custo operacional, maior facilidade de avaliação e satisfatória eficiência (FURLANI et al., 2000). Os resultados em solução nutritiva devem ser então corroborados com o comportamento dos cultivares em campo, uma vez que se considera nessa avaliação apenas o excesso de alumínio.

Segundo Parentoni et al. (2000), o programa da Embrapa visando ao desenvolvimento de genótipos de milho adaptados a solos ácidos baseia-se no binômio tolerância ao alumínio em solução nutritiva e produção em solos ácidos e férteis. Esses autores ressaltam que a seleção no campo é feita para um complexo determinante de solo ácido, havendo outros fatores envolvidos, além da concentração de alumínio. Para a obtenção de 45\% de saturação de alumínio no solo, por exemplo, os níveis de fósforo, cálcio e magnésio não podem estar elevados.

A discriminação de genótipos de milho em solução nutritiva é de grande valia em programas de melhoramento, quando se necessita avaliar elevado número de genótipos; possibilita, ainda, a estimativa da capacidade geral e específica de combinação de linhagens e de outros parâmetros genéticos para o caráter tolerância ao alumínio tóxico.

BAHIA-FILHO et al. (1997) apresentaram uma revisão histórica de pesquisa e desenvolvimento efetuados pelo Centro Nacional de Pesquisa de Milho e Sorgo da Embrapa, relacionados à identificação, à utilização e ao impacto econômico de germoplasma de milho adaptado a condições de solos ácidos. Resultados obtidos por MACHADO et al. (1998) quanto à tolerância a Al em milho crioulo revelaram ampla variabilidade entre germoplasmas de grãos duros, dentados ou semidentados - nem sempre com correspondência para produção de grãos. As variedades que se apresentaram tanto produtivas quanto tolerantes a $\mathrm{Al}$ servem para recomendação direta ao plantio em locais onde a acidez do solo é problemática, enquanto aquelas que são tolerantes a $\mathrm{Al}$, porém pouco produtivas, serão fontes genéticas para esse caráter de tolerância que poderá ser incorporado na formação de compostos aliando alta capacidade produtiva e tolerância ao Al.

Assim, o presente trabalho tem por objetivo avaliar linhagens e híbridos de milho do programa de melhoramento do Instituto Agronômico quanto à tolerância ao alumínio tóxico em casa de vegetação e obter estimativas de parâmetros genéticos (capacidade de combinação e heterose) do caráter crescimento líquido da radícula (CLR).

\section{MATERIAL E MÉTODOS}

Dez linhagens, denominadas L 02, L 03, L 04, L 05, L 06, L 08, L 09, L 10, L 11 e L 13, derivadas, respectivamente, de MJ 274-2, CML 109, CML 110, CML 114, CML 115, CML 119, CML 124, CML 137, CML 138 e CML 153, foram cruzadas em esquema dialélico completo. Os 45 híbridos simples e as linhagens foram avaliados em solução nutritiva, sob delineamento de blocos casualizados com quatro repetições, no Núcleo Experimental de Campinas (IAC), em 1997, utilizandose como controles linhagens de IAC Taiúba sensível e tolerante. Cada parcela foi constituída de dez plântulas, totalizando 40 plântulas por genótipo.

A solução nutritiva foi composta de mg. $\mathrm{L}^{-1}$ : Ca (140), K (90), $\mathrm{Mg}(20), \mathrm{N}_{-} \mathrm{NO}_{3}$ (148), N-NH 4 (18), $\mathrm{S}_{-} \mathrm{SO}_{4}(20), \mathrm{P}_{-} \mathrm{PO}_{4}(1,0), \mathrm{Fe}(1,5), \mathrm{B}(0,10), \mathrm{Cu}(0,02)$, Mn $(0,20)$, Mo $(0,03), \mathrm{Zn}(0,06)$ e $\mathrm{Al}(4,5) \mathrm{com} \mathrm{pH}$ inicial ao redor de 4,0 (Furlani e Furlani, 1988). Para o crescimento das plantas utilizaram-se recipientes plásticos, com capacidade para armazenar $15 \mathrm{~L}$ de solução nutritiva, tampados com placas de acrílico perfuradas para acomodação das plântulas. Para a avaliação da tolerância ao $\mathrm{Al}$ adotou-se o seguinte método: (a) sementes de milho foram colocadas para germinar em rolos de papel-toalha umedecido; (b) três a quatro dias após o início da germinação, transferiramse as plântulas para solução nutritiva, eliminando as raízes seminais laterais e medindo o comprimento da radícula (CR inicial); (c) cerca de uma semana após o transplante, colheram-se as plantas e mediu-se novamente o comprimento da radícula (CR final); (d) com os dados médios do CR inicial e do CR final, estimou-se o crescimento líquido da radícula (CLR); (e) com os dados de CLR obtidos para cada material $\left(C L R_{x}\right)$ e para os controles sensível $\left(\mathrm{CLR}_{\mathrm{s}}\right)$ e tolerante $\left(\mathrm{CLR}_{\mathrm{T}}\right)$, calculou-se o índice relativo da tolerância ao $\mathrm{Al}\left(\mathrm{ITR}_{\mathrm{Al}}\right)$ pela expressão:

$$
\operatorname{ITR}_{\mathrm{Al}}=\left[\frac{\left(\mathrm{CLR}_{\mathrm{X}}-\mathrm{CLR} \mathrm{S}_{\mathrm{S}}\right)}{\left(\mathrm{CLR}_{\mathrm{T}}-\mathrm{CLR}_{\mathrm{S}}\right)} \times 4,0\right]+1,0
$$

Dessa maneira, os controles sensível e tolerante assumem valores de ITR $_{\mathrm{Al}}$ iguais a 1,0 e 5,0 respectivamente.

Os dados de CLR foram submetidos a análises da variância e dialélica pelo modelo de Griffing (1956) método 4 (pais e híbridos $\mathrm{F}_{1}$ ), obtendo-se estimativas 
Quadro 1. Médias do comprimento líquido da radícula (CLR), heterose em relação à média dos pais do CLR (h\%) e índice de tolerância relativa (ITR) à toxicidade de alumínio de 45 híbridos simples de milho, das testemunhas e das linhagens genitoras, estimadas de ensaios em solução nutritiva. Campinas, 1997

\begin{tabular}{|c|c|c|c|c|c|}
\hline Tratamento & Híbrido simples/ Linhagem & CLR & $\mathrm{h}$ & ITR & $\mathrm{PG}^{(1)}$ \\
\hline & & $\mathrm{cm}$ & $\%$ & & kg.ha-1 \\
\hline 1 & HS 02X03 & 7,70 l-r & 35,8 & 1,80 & 5.954 \\
\hline 2 & HS $02 \times 04$ & $8,08 \mathrm{k}-\mathrm{r}$ & 73,0 & 1,92 & 6.408 \\
\hline 3 & HS 02X05 & 7,92 1-r & 6,2 & 1,85 & 6.833 \\
\hline 4 & HS 02X06 & $11,70 \mathrm{c}-\mathrm{p}$ & 25,5 & 3,05 & 7.328 \\
\hline 5 & HS 02X08 & $8,22 \mathrm{k}-\mathrm{r}$ & 102,0 & 1,98 & 5.710 \\
\hline 6 & HS 02X09 & $14,60 \mathrm{~b}-\mathrm{j}$ & 51,5 & 4,19 & 6.633 \\
\hline 7 & HS 02X10 & 13,72 b-1 & 78,0 & 3,73 & 7.715 \\
\hline 8 & HS 02X11 & $8,001-\mathrm{r}$ & 87,4 & 1,72 & 7.002 \\
\hline 9 & HS $02 \times 13$ & $7,981-r$ & 13,0 & 1,91 & 7.057 \\
\hline 10 & HS 03X04 & 6,38 o-r & 0,95 & 1,35 & 3.553 \\
\hline 11 & HS 03X05 & $12,45 \mathrm{c}-\mathrm{o}$ & 36,7 & 3,31 & 6.178 \\
\hline 12 & HS $03 \times 06$ & $15,75 \mathrm{a}-\mathrm{g}$ & 43,6 & 4,32 & 7.233 \\
\hline 13 & HS 03X08 & $8,42 \mathrm{j}-\mathrm{r}$ & 47,2 & 2,01 & 7.266 \\
\hline 14 & HS 03X09 & $17,28 \mathrm{a}-\mathrm{d}$ & 53,1 & 4,81 & 6.921 \\
\hline 15 & HS $03 \times 10$ & $12,02 \mathrm{c}-\mathrm{o}$ & 28,4 & 3,23 & 8.232 \\
\hline 16 & HS 03X11 & $9,20 \mathrm{~h}-\mathrm{r}$ & 55,4 & 2,28 & 7.818 \\
\hline 17 & HS 03X13 & $12,70 \mathrm{~b}-\mathrm{o}$ & 45,8 & 3,35 & 7.547 \\
\hline 18 & HS 04X05 & $10,00 \mathrm{f}-\mathrm{r}$ & 23,3 & 2,41 & 7.006 \\
\hline 19 & HS 04X06 & $9,05 \mathrm{i}-\mathrm{r}$ & $-9,2$ & 2,24 & 7.665 \\
\hline 20 & HS 04X08 & $9,05 \mathrm{i}-\mathrm{r}$ & 91,7 & 2,41 & 8.059 \\
\hline 21 & HS 04X09 & 16,95 a-e & 64,8 & 4,70 & 7.686 \\
\hline 22 & HS 04X10 & $11,02 \mathrm{~d}-\mathrm{q}$ & 31,8 & 2,88 & 8.992 \\
\hline 23 & HS 04X11 & $7,42 \mathrm{l}-\mathrm{r}$ & 50,8 & 1,65 & 7.951 \\
\hline 24 & HS $04 X 13$ & $8,18 \mathrm{k}-\mathrm{r}$ & 6,1 & 1,90 & 7.441 \\
\hline 25 & HS 05X06 & $13,42 \mathrm{~b}-\mathrm{m}$ & 5,2 & 3,66 & 5.315 \\
\hline 26 & HS 05X08 & 12,82 b-n & 70,7 & 3,50 & 6.796 \\
\hline 27 & HS 05X09 & $15,48 \mathrm{~b}-\mathrm{h}$ & 18,4 & 4,51 & 7.508 \\
\hline 28 & HS $05 \times 10$ & 16,62 a-e & 49,0 & 4,62 & 7.448 \\
\hline 29 & HS 05X11 & $6,95 \mathrm{n}-\mathrm{r}$ & $-9,8$ & 1,45 & 7.419 \\
\hline 30 & HS $05 \times 13$ & $11,40 c-q$ & 8,6 & 2,95 & 7.286 \\
\hline 31 & HS 06X08 & 16,48 a-e & 75,9 & 4,83 & 6.809 \\
\hline 32 & HS 06X09 & 21,92 & 46,8 & 6,53 & 7.474 \\
\hline 33 & HS 06X10 & 16,25 a-f & 24,9 & 4,51 & 8.350 \\
\hline 34 & HS 06X11 & 9,62 g-r & 0,5 & 2,36 & 7.734 \\
\hline 35 & HS 06X13 & $13,08 \mathrm{~b}-\mathrm{n}$ & 5,8 & 3,56 & 7.759 \\
\hline 36 & HS 08X09 & $17,58 \mathrm{a}-\mathrm{c}$ & 81,5 & 5,16 & 7.133 \\
\hline 37 & HS 08X10 & $9,62 \mathrm{~g}-\mathrm{r}$ & 24,0 & 2,40 & 8.282 \\
\hline 38 & HS 08X11 & 7,42 l-r & 71,8 & 1,76 & 6.867 \\
\hline 39 & HS 08X13 & $12,45 \mathrm{c}-\mathrm{o}$ & 75,1 & 3,34 & 7.370 \\
\hline 40 & HS 09X10 & $14,42 \mathrm{~b}-\mathrm{k}$ & 8,22 & 3,96 & 5.404 \\
\hline 41 & HS 09X11 & 16,62 a-e & 68,1 & 4,80 & 8.253 \\
\hline 42 & HS 09X13 & $18,90 \mathrm{ab}$ & 49,1 & 5,43 & 8.003 \\
\hline 43 & HS 10X11 & $15,05 \mathrm{~b}-\mathrm{i}$ & 89,1 & 4,17 & 8.899 \\
\hline 44 & HS $10 \mathrm{X} 13$ & 13,62 b-m & 26,7 & 3,55 & 8.253 \\
\hline 45 & HS $11 X 13$ & $8,38 \mathrm{j}-\mathrm{r}$ & 14,6 & 1,96 & 7.944 \\
\hline 46 & L 02 & $4,02 \mathrm{r}$ & - & 0,56 & - \\
\hline 47 & L 03 & $7,32 \mathrm{~m}-\mathrm{r}$ & - & 1,66 & - \\
\hline 48 & L 04 & $5,32 \mathrm{qr}$ & - & 0,98 & - \\
\hline 49 & L 05 & 10,90 e-q & - & 2,85 & - \\
\hline 50 & L 06 & $14,62 \mathrm{~b}-\mathrm{j}$ & - & 4,03 & - \\
\hline 51 & L 08 & $4,12 \mathrm{r}$ & - & 0,53 & - \\
\hline 52 & L 09 & $15,25 \mathrm{~b}-\mathrm{i}$ & - & 4,40 & - \\
\hline 53 & L 10 & $11,40 \mathrm{c}-\mathrm{q}$ & - & 3,06 & - \\
\hline 54 & L 11 & $4,52 \mathrm{r}$ & - & 0,73 & - \\
\hline 55 & L 13 & $10,10 \mathrm{f}-\mathrm{r}$ & - & 2,66 & - \\
\hline 56 & $\mathrm{TT}^{(2)}$ & $17,52 \mathrm{a}-\mathrm{c}$ & - & 5,0 & - \\
\hline 57 & $\mathrm{TS}^{(2)}$ & $5,35 \mathrm{p}-\mathrm{r}$ & - & 1,0 & - \\
\hline Média & & 11,45 & - & 3,0 & 7.255 \\
\hline CV (\%) & & 19,1 & - & - & 9,4 \\
\hline dms (Tukey a 5\%) & 6,4 & - & - & 1.122 & \\
\hline
\end{tabular}

$\left(^{1}\right)$ Peso de grãos em quatro localidades paulistas (Paterniani et al., 2000). ( ${ }^{2}$ ) IAC Taiúba tolerante e sensível ao Al tóxico respectivamente. 
da capacidade geral (CGC) e específica (CEC) de combinação. Para comparações de médias empregou-se o teste de Tukey a $5 \%$ de probabilidade.

A heterose $(\mathrm{h} \%)$ foi calculada pela diferença entre a média do CLR do híbrido simples $\left(\mathrm{F}_{1}\right)$ e a média do CLR das linhagens genitoras. Utilizou-se o programa Genes para as análises genéticas (Cruz, 1997).

Os valores de produtividade de grãos dos híbridos simples foram obtidos em quatro localidades paulistas (Campinas, Mococa, Ribeirão Preto e Assis), em 1997, em experimentos com solos corrigidos e apresentados por PATERniani et al. (2000).

\section{RESULTADOS E DISCUSSÃO}

Os híbridos simples que se destacaram quanto à tolerância à toxicidade de alumínio, com valores elevados de CLR e ITR igual ou maior que 4,0 foram: HS 02X09, HS 03X06, HS 03X09, HS 04X09, HS 05X09, HS 05X10, HS 06X08, HS 06X09, HS 06X10, HS 08X09, HS 09X11, HS 09X13 e HS 10X11. Dentre as linhagens, destacaram-se L 06, L 09 e L 10 (Quadro 1).

As estimativas da heterose de CLR em relação à média dos pais (h\%) variaram de $-9,2 \%$ a $102,0 \%$, apresentado metade dos cruzamentos heterose maior que $40 \%$ (Quadro 1). De acordo com os resultados de Lima et al. (1995), verificaram-se elevados valores de heterose em alguns cruzamentos entre linhagens sensíveis ao $\mathrm{Al}$, atribuídos à recuperação do vigor perdido no processo de endogamia pela ação de genes deletérios com efeitos epistáticos; genes deletérios que afetam a planta podem também inibir o desenvolvimento da radícula.

Observando-se os valores da produtividade de grãos em solos corrigidos dos mesmos híbridos avaliados em solução nutritiva, ressalta-se que alguns de elevada produtividade, que não diferiram das testemunhas comerciais (PATERNIANI, 2000), também apresentaram elevados valores de CLR e ITR, como HS 10X11, HS 09X13, HS 09X11, HS 06X10.

$\mathrm{O}$ quadro 2 mostra a análise da variância com desdobramento de CGC e CEC, cujas fontes de variação foram significativas $(\mathrm{P}<0,01)$. Observou-se a preponderância da CGC, sendo o QM da CGC 12 vezes maior que o QM da CEC; confirma-se, portanto, a maior importância de efeitos aditivos na expressão da tolerância ao alumínio tóxico em milho, embora efeitos de dominância também estejam presentes (efeito da CEC significativo).

Magnavaca (1982), Prioli (1987) e Lima et al. (1995) também obtiveram estimativas da capacidade de combinação quanto à tolerância ao $\mathrm{Al}$ em dialélicos de linhagens de milho e concluíram que a maior porção da variabilidade desse caráter deve-se à CGC, com menor importância da $\mathrm{CEC}$, embora efeitos não aditivos também tenham sido detectados.

Quadro 2. Análise da variância do comprimento líquido da radícula (CLR), em centímetros, de 45 híbridos simples de milho resultantes de dialélico completo entre 10 linhagens, de acordo com o método 4 - modelo de Griffing (1956)

\begin{tabular}{lrrr}
\hline \multicolumn{1}{c}{ FV } & GL & QM & F \\
Tratamento & 54 & 50,065 & $10,29^{* *}$ \\
CGC & 9 & 210,910 & $43,36^{* *}$ \\
CEC & 45 & 17,896 & $3,68^{* *}$ \\
Resíduo & 162 & 4,864 & \\
\hline
\end{tabular}

**: Significativo a $1 \%$.

Quadro 3. Estimativas da capacidade geral de combinação $\left(\mathrm{g}_{\mathrm{i}}\right)$ de dez linhagens de milho para o caráter comprimento líquido da radícula (CLR), segundo Griffing (1956)

\begin{tabular}{ccc}
\hline Linhagem & $\mathrm{g}_{\mathrm{i}}$ & CLR \\
\hline L 02 & 01 & $\mathrm{~cm}$ \\
L 03 & 02 & $-2,49$ \\
L 04 & 03 & $-0,78$ \\
L 05 & 04 & $-2,42$ \\
L 06 & 05 & 0,25 \\
L 08 & 06 & 2,55 \\
L 09 & 07 & $-1,30$ \\
L 10 & 08 & 4,86 \\
L 1 & 09 & 1,60 \\
L 13 & 10 & $-2,35$ \\
\hline
\end{tabular}

As estimativas da capacidade geral de combinação (g.) das linhagens apresentadas no quadro 3 permitiram identificar a L 06 e a L 09 como fontes de tolerância ao alumínio tóxico. A L 10 também apresentou valor positivo de $\mathrm{g}_{\mathrm{i}}$ para CLR e elevada produtividade em determinadas combinaçôes híbridas. Destacou-se, ainda, pelo maior valor de CGC para produtividade de grãos (Paterniani et al., 2000).

No quadro 4, que apresenta as estimativas da capacidade específica de combinação $\left(s_{\mathrm{ij}}\right)$ das 45 combinações, ressaltam os seguintes híbridos: HS 10X11, HS 06X08, HS 05X10, HS 02X10, HS 04X09 e HS 06X09. O HS 10X11, denominado IAC 21, vemse destacando quanto à produtividade de grãos no programa de melhoramento do IAC e apresentou bom desempenho no Ensaio Nacional de Milho em 1999/ 2000, região Centro do país. 
Quadro 4. Estimativas da capacidade específica de combinação $\left(s_{\mathrm{ij}}\right)$ de dez linhagens de milho para o caráter comprimento líquido da radícula (CLR), segundo Griffing, 1956

\begin{tabular}{|c|c|c|c|c|c|c|c|c|c|c|}
\hline \multicolumn{11}{|c|}{ Capacidade específica de combinação $\left(\mathrm{S}_{\mathrm{ij}}\right)$} \\
\hline & 1 & 2 & 3 & 4 & 5 & 6 & 7 & 8 & 9 & 10 \\
\hline 1 & - & $-0,47$ & 1,56 & $-1,28$ & 0,20 & 0,57 & 0,79 & 3,17 & 1,40 & $-1,05$ \\
\hline 2 & & - & $-1,86$ & 1,54 & 2,53 & $-0,95$ & 1,75 & $-0,25$ & 0,88 & 1,95 \\
\hline 3 & & & - & 0,73 & $-2,52$ & 1,33 & 3,07 & 0,40 & 0,75 & $-0,92$ \\
\hline 4 & & & & - & $-0,82$ & 2,43 & $-1,08$ & 3,32 & $-2,39$ & $-0,38$ \\
\hline 5 & & & & & - & 3,78 & 3,06 & 0,65 & $-2,02$ & $-1,00$ \\
\hline 6 & & & & & & - & 2,57 & $-2,13$ & $-0,38$ & 2,22 \\
\hline 7 & & & & & & & - & $-3,49$ & 2,66 & 2,51 \\
\hline 8 & & & & & & & & - & 4,35 & 0,49 \\
\hline 9 & & & & & & & & & - & $-0,80$ \\
\hline 10 & & & & & & & & & & - \\
\hline
\end{tabular}

$1=\mathrm{L} 02 ; 2=\mathrm{L} 03 ; 3=\mathrm{L} 04 ; 4=\mathrm{L} 05 ; 5=\mathrm{L} 06 ; 6=\mathrm{L} 08 ; 7=\mathrm{L} 09 ; 8=\mathrm{L} 10 ; 9=\mathrm{L} 11 ; 10=\mathrm{L} 13$.

Alguns híbridos que se destacaram quanto ao CLR em solução nutritiva e ao ITR apresentaram elevada produtividade em ensaios de campo em solo corrigido, como HS 10X11, HS 09X13, HS 09X11, HS 06X10, HS 06X09, HS 05X10, HS 05X09 e HS 04X09. Com isso, comprova-se que é possível associar tolerância à toxicidade de alumínio com produtividade de grãos elevada, discordando de hipóteses que preconizam tolerância ao alumínio em milho como característica apenas de cultivares rústicos, de baixa capacidade produtiva.

\section{CONCLUSÕES}

1. As linhagens L 09 e L 06 constituem-se em fontes de tolerância ao $\mathrm{Al}$ tóxico, destacando-se, ainda, a L 10.

2. A expressão da tolerância ao $\mathrm{Al}$ com base no comprimento líquido da radícula deve-se, principalmente, a efeitos gênicos aditivos, embora efeitos de dominância também estejam presentes.

3. Identificaram-se híbridos de milho tolerantes à toxicidade de alumínio em solução nutritiva com elevada produtividade em solos corrigidos.

\section{REFERÊNCIAS BIBLIOGRÁFICAS}

BAHIA-FILHO, A.F.C.; MAGNAVACA, R.; SCHAFFERT, R.E.; ALVES, V.M.C. Identification, utilization, and economic impact of maize germplasm tolerant to low levels of phosphorus and toxic levels of exchangeable aluminum in Brazilian soils. In: A.C. Moniz et al. (Eds.). Plant soil interactions at low $p H$. Campinas: Brazilian Soil Science Society, 1997. p.59-70

CRUZ, C.D. Programa Genes: Aplicativo computacional em genética e estatística. Viçosa: Universidade Federal de Viçosa, 1997. 442p.
FURLANI, A.M.C.; FURLANI, P.R. Composição e phH de soluçôes nutritivas para estudos fisiológicos eseleção de plantas em condiçōes nutricionais adversas. Campinas: Instituto Agronômico, 1988. 34 p. (Boletim Técnico, 121)

FURLANI, P.R.; DUARTE, A.P.; PATERNIANI, M.E.A.G.Z. Tolerância ao alumínio em cultivares de milho. In: DUARTE, A.P.; PATERNIANI, M.E.A.G.Z. (Coords). Fatores bióticos e abioticos em cultivares de milho e estratificação ambiental: avaliação IAC/CATI/Empresas - 1999-2000. Campinas: Instituto Agronômico, 2000, p. 19-29. (Boletim Científico, 5)

FURLANI, P.R.; LIMA, M.; MIRANDA, L.T.; MIRANDA, L.E.C.; SAWAZAKI, E.; MAGNAVACA, R. Avaliação de linhagens materiais comerciais e duas populaçōes de milho para tolerância a alumínio. Pesquisa Agropecuária Brasileira, Brasília, v.21, p.655-660, 1986.

GRANADOS, G.; PANDEY, S.; CEBALLOS, H. Response to selection for tolerance to acid soils in a tropical maize population. Crop Science, Madison, v.33, p.936-940, 1993.

GRIFFING, B. Concept of general and specific combining ability in relation to diallell crossing systems. Australian Journal of Biological Sciences, East Melbourne, v.9, p.463493, 1956.

LIMA, M.; MIRANDA-FILHO, J.B.; FURLANI, P.R. Diallel cross among inbred lines of maize differing in aluminum tolerance. Revista Brasileira de Genética, Ribeirão Preto, v.18, n.4, p.579-584, 1995.

LOPES, M.A.; MAGNAVACA, R.; BAHIA-FILHO, A.F.C.; GAMA, E.E.G. Avaliação de populaçōes de milho e seus cruzamentos para tolerância a toxidez de alumínio em solução nutritiva. Pesquisa Agropecuária Brasileira, Brasília, v.22, p.257-263, 1987. 
MACHADO, A. T.; MACHADO, C.T. de T. ; FURLANI, P.R. Avaliação e caracterização de variedades locais de milho para condições adversas de ambiente. In: SOARES, A.C.; MACHADO, A.T.; SILVA, B. de M.; WEID, J.M. von Der (Orgs.). Milho crioulo: conservação e uso da biodiversidade. Rio de Janeiro: AS-PTA - Assessoria e serviços a projetos em agricultura alternativa, 1998. p.151-185.

MAGNAVACA, R. Genetic variability and the inheritance of aluminum tolerance in maize (Zea mays L.). Lincoln, NE, 1982. 135p. Tese (Doutorado) - University of Nebraska.

MAGNAVACA, R.; BAHIA-FILHO, A.F.C. Seleção de milho para tolerância a alumínio. In: SIMPÓSIO INTERNACIONAL SOBRE ESTRESSE AMBIENTAL: O MILHO EM PERSPECTIVA, 1995, Belo Horizonte. Anais... Sete Lagoas: EMBRAPACNPMS/CIMMYT/UNDP, 1995. p.369-394.

PANDEY, S.; CEBALLOS, H.; MAGNAVACA, R.; BAHIAFILHO, A.F.C.; DUQUE-VARGAS, J.; VINASCO, L.E. Genetics of tolerance to soil acidity in tropical maize. Crop Science, Madison, v.34, p.1511-1514, 1994.
PARENTONI, S.; ALVES, V.M.C.; VASCONCELOS, C.A.; GAMA, E.E.G.; SANTOS, M.X.; PACHECO, C.A.P.; MEIRELLES, W.F. Seleção de milho para tolerância a solos ácidos: técnicas e critérios para diferenciação de cultivares. In: DUARTE, A.P.;

PATERNIANI, M.E.A.G.Z. (Coords.). Fatores bióticos e abióticos em cultivares de milho e estratificação ambiental: avaliação IAC/CATI/Empresas - 1999-2000. Campinas: Instituto Agronômico, 2000. p.11-17. (Boletim Científico, 5)

PATERNIANI, M.E.A.G.Z.; SAWAZAKI, E.; DUDIENAS, C.; DUARTE, A.P.; GALLO, P.B. Diallel crosses among maize lines with emphasis on resistance to foliar diseases. Genetics and Molecular Biology, Ribeirão Preto, v.23, n.2, p.381-385, 2000.

PRIOLI, A. J. Análise genética da tolerância à toxidez do alumínio em milho. Campinas, 1987. 182f. Tese (Doutorado) -Universidade Estadual de Campinas.

SAWAZAKI, E.; FURLANI, P.R. Genética da tolerância ao alumínio em linhagens de milho cateto.Bragantia, Campinas, v.46, n.2, p.269-278, 1987. 